\title{
Is childhood meat eating associated with better later adulthood cognition in a developing population?
}

\author{
Michelle Heys $\cdot$ Chaoqiang Jiang $\cdot$ C. Mary Schooling • \\ WeiSen Zhang $\cdot$ Kar Keung Cheng $\cdot$ Tai Hing Lam • \\ Gabriel M. Leung
}

Received: 6 July 2009/Accepted: 18 May 2010/Published online: 6 June 2010

(c) The Author(s) 2010. This article is published with open access at Springerlink.com

\begin{abstract}
Inadequate childhood nutrition is associated with poor short-term academic and cognitive outcomes. Dietary supplementation with meat is associated with better cognitive outcome in children. Whether childhood nutrition has life long effects on cognitive function is unclear. We examined the association of childhood meat eating with adulthood cognitive function in southern China where the older population lived through significant hardship during their early years. Multivariable linear regression was used in a cross-sectional study of 20,086 Chinese men and women aged $\geq 50$ years from the Guangzhou Biobank Cohort Study (phases 2 and 3) 2005-8. We assessed the association of childhood meat eating with delayed 10-word and immediate recall score. Adjusted for age, sex, education, childhood and adulthood socio-economic position and current physical activity, childhood meat eating almost daily, when compared to yearly or never childhood meat eating, was positively associated with delayed recall score (additional number of words recalled out of $10=0.22$ [95\% confidence interval $=0.11-0.31]$ ). Similarly adjusted, childhood meat eating about once a month, about once a week and almost daily were positively associated with immediate recall score (additional number of words recalled out of $30=0.38$
\end{abstract}

M. Heys · C. M. Schooling ( $₫)$ - T. H. Lam · G. M. Leung Department of Community Medicine, and School of Public Health, The University of Hong Kong, 21 Sassoon Road, Pokfulam, Hong Kong SAR, China

e-mail: cms1@hkucc.hku.hk

C. Jiang $\cdot$ W. Zhang

Guangzhou Occupational Diseases Prevention and Treatment Centre, Guangzhou Number 12 Hospital, Guangzhou, China

\section{K. K. Cheng}

Department of Public Health and Epidemiology,

University of Birmingham, Birmingham, UK
[0.23-0.54], 0.73 [0.56-0.89] and 0.76 [0.55-0.98] respectively). More frequent childhood meat eating was associated with better cognition through to old age. If confirmed, these results highlight the importance of adequate childhood nutrition and they also emphasise the childhood and adolescent antecedents of adult disease, with corresponding public health implications for healthy aging.

Keywords Aged $\cdot$ Childhood $\cdot$ China $\cdot$ Cognition · Cross-sectional studies $\cdot$ Dementia $\cdot$ Nutrition

\begin{tabular}{|c|c|}
\hline \multicolumn{2}{|c|}{ Abbreviations } \\
\hline $\mathrm{AD}$ & Alzheimer's disease \\
\hline CERAD & $\begin{array}{l}\text { Consortium to Establish a Registry for } \\
\text { Alzheimer's Disease }\end{array}$ \\
\hline GBCS & Guangzhou Biobank Cohort Study \\
\hline GHHARE & $\begin{array}{l}\text { Guangzhou Health and Happiness } \\
\text { Association for the Respectable Elders }\end{array}$ \\
\hline IPAQ & International physical activity questionnaire \\
\hline IPAQ-C & $\begin{array}{l}\text { Chinese version of International physical } \\
\text { activity questionnaire }\end{array}$ \\
\hline IRR & Incident rate ratio \\
\hline MCI & Mild cognitive impairment \\
\hline MET & Metabolic equivalent \\
\hline PRC & People's Republic of China \\
\hline SD & Standard deviations \\
\hline SEP & Socio-economic position \\
\hline USD & United States dollar \\
\hline
\end{tabular}

Introduction

An estimated $60 \%$ of people with dementia worldwide live in developing countries [1]. The number of people affected by dementia is expected to increase to a greater extent in 
developing countries, such as China, than in developed countries (300\% compared with 100\% between 2001 and 2040) [1]. By the year 2036, 20\% of the population of China will be aged over 65 years, double that of $10 \%$ in the year 2000 [2]. As the population ages it is particularly important to understand predisposing factors to debilitating age-related disorders such as cognitive impairment, so that effective public health interventions can be developed.

Early life exposures may contribute to adulthood cognitive impairment either by affecting brain structure and/or function such that there is greater resilience to degeneration, i.e., "cognitive reserve hypothesis" or by increasing vulnerability to neurodegenerative processes [3]. In addition, there is growing evidence that early life exposures, such as childhood socioeconomic status or skeletal growth are related to cognitive function throughout life, including later adulthood [4-6]. However, the specific aspect(s) of early conditions underlying these associations are not clear. Some evidence exists to suggest there may be an association between childhood nutrition and cognitive function, although this is largely limited to studies on young children, where animal protein intake has been positively associated with earlier walking in infants [7, 8] and dietary supplementation with meat in infants and children in developing countries associated with better cognitive function up to school age $[9,10]$, independent of iron status $[8,9]$. Protein energy supplementation from non-meat sources (vegetables, milk and sugar) given from birth to 24 months in developing populations has been positively associated with cognitive function in early adulthood (mean age 32 years), especially in women [11]. It remains unclear whether childhood nutrition, proxied by meat eating, is associated with cognitive function in later adulthood.

Here we examined the association of childhood meat eating with later life cognitive function in an older population of Southern Chinese men and women. We tested the hypothesis that increased frequency of childhood meat eating is associated with better later adulthood cognitive function using the 10-word list learning task. This task was taken from the CERAD (Consortium to Establish a Registry for Alzheimer's Disease) test battery designed to assess cognition function in older people [12]. The CERAD tests cover general cognition, confrontational naming, semantic fluency, constructional ability and new learning ability. The adapted CERAD 10-word list learning task has been validated as a culturally and educationally sensitive tool for identifying dementia in population based research in developing countries [13]. The immediate recall component of the adapted CERAD 10-word learning task tests new learning ability. In addition the delayed recall component of the 10-word list learning task has been validated as a sensitive tool for identifying mild cognitive impairment (MCI) [14], which is sub-clinical cognitive decline distinct from normal ageing that does not interfere with daily life, and may affect several cognitive domains, including general cognition and executive functioning [1517]. Amnesic-MCI is a sub-type of MCI characterized by memory deficits, corresponding to poor delayed recall on the 10-word list-learning task. Both MCI and amnesic-MCI are conditions with a high risk of progressing to Alzheimer's disease or dementia [16-18], probably because recall activity is centered in the entorhinal cortex and hippocampus, where the earliest neuropathological changes in Alzheimer's disease occur [14]. Annual conversion rates to dementia from MCI vary from about 10 to $15 \%$ in clinic based studies to $5-10 \%$ in population-based studies, with possibly higher rates for amnesic-MCI [17, 18].

\section{Methods}

\section{Materials}

The Guangzhou Biobank Cohort Study is an ongoing collaboration among the Guangzhou People's Number 12 Hospital, the Universities of Hong Kong and Birmingham and has been described in detail elsewhere [19]. Recruitment of participants was carried out in 3 phases and draws from "The Guangzhou Health and Happiness Association for the Respectable Elders" (GHHARE), a community social and welfare association unofficially aligned with the municipal government where membership is open to older persons for a monthly fee of 4 Yuan (50 US cents). About $7 \%$ of permanent Guangzhou residents aged 50 years and over are members of GHHARE, of whom $11 \%$ (about 10,000 participants) enrolled each time for phases one, two and three and were included if they were capable of consenting, ambulatory, and not receiving treatment modalities which if omitted may result in immediate life threatening risk, such as chemotherapy or radiotherapy for cancer, or dialysis for renal failure. Those with less immediate risk, such as a history of vascular disease or associated risk factors, including diabetes and hypertension, were not excluded from the study. The interview protocol was changed in phase 2 (recruited from April 2005 to May 2006) to include questions regarding the participant's family background and childhood experiences, which were also included in phase 3 (recruited from September 2006 to January 2008). The Guangzhou Medical Ethics Committee of the Chinese Medical Association approved the study and all participants gave written, informed consent prior to participation.

Participants underwent a detailed medical interview, including questions regarding lifestyle and socio-economic position (SEP), and a physical examination. Standing 
height was measured without shoes to the nearest $0.1 \mathrm{~cm}$. The 10-word list-learning task was adapted to be culturally appropriate. Four words in this test were taken from the original CERAD English language test [13]: "arm", "letter", "ticket" and "grass". "Pole", "shore", "cabin" and "engine" were replaced with "corner", "stone", "book" and "stick" as in the adapted CERAD 10-word list learning task [13], whilst "butter" and "queen" were replaced by "soy sauce" and "chairman" as these are more culturally appropriate. During the learning phase the 10-word list was read out to the participant who was then asked to immediately recall the words they remembered, this was repeated 3 times giving an immediate recall, or learning score out of 30. Following a 5-minute period of distraction, during which the interview was continued, the participant was then asked to recall as many of the 10 words as they were able to, giving a delayed recall score out of 10 .

Historical and nutritional setting:

Participants in GBCS grew up in China around the mid 20th century. Great social and economic change has occurred throughout their lifetime. China is currently experiencing very rapid economic growth, from essentially pre-industrial conditions prevalent until the mid 20th century [20, 21]. Between 1952 and 1979 annual per capita animal food intake increased marginally from 11 to $16.5 \mathrm{~kg}$ respectively $[22,23]$, with religion playing little role in influencing diet before or after the establishment of the PRC. Annual per capita intake of animal foods and meat in China were 13.2 and $9.1 \mathrm{~kg}$ respectively in 1970 and 34.8 and $25.9 \mathrm{~kg}$ respectively in 1990 , much lower than for example the United States (annual per capita meat in take $112.2 \mathrm{~kg}$ in 1990) [22, 23].

\section{Outcome}

The main outcome was the delayed 10-word recall score (out of 10) on the adapted CERAD 10-word learning task. The secondary outcomes were immediate 10 -word recall score (out of 30), and presence of amnesic-MCI, which is typically defined as a delayed 10 -word recall score of one or 1.5 standard deviations (SD) below the mean for the population being studied. Here our sample had a mean delayed 10-word recall score of 5.6 (SD 1.9). One or 1.5 SD below the mean would correspond to a score of 3.7 or 2.8 respectively. Amnesic-MCI was here defined as 3 or less out of 10 on the delayed 10-word recall score.

\section{Childhood SEP}

We selected a broad marker of family living conditions, similar to proxies such as car owner-ship or housing tenure in the West, using possession of simple, notable items appropriate to China in the mid-twentieth century, based on sociological accounts of life in southern China at that time [24-26]. We asked about parental possession of just three items during the participants' childhood: a watch, a sewing machine and a bicycle. Childhood SEP was categorized as low (no such parental possessions), medium (1 or 2) and high (all 3), as we have used previously [27].

\section{Exposure}

Childhood meat eating was assessed by asking participants whether they ate meat as a child with answers in Chinese which translate as "never", "about once a year", "about once a month", "about once a week" or "almost daily". Less than $1 \%$ reported "never" eating meat in childhood therefore the categories for "never" and "yearly" were combined to create a 4 point scale: "Never/yearly", "about once a month", "about once a week" and "almost daily".

Statistical analysis

Pearson $\chi^{2}$ test (categorical variables) and analysis of covariance (continuous variables) were used to assess unadjusted associations between childhood meat eating and participant characteristics. Multivariable linear regression was used to assess the association of childhood meat eating with delayed 10-word and immediate recall score, from which we reported adjusted difference in number of words recalled. Due to the relatively high prevalence of amnesicMCI (12.6\% overall) Poisson regression (with robust variance) was used to assess the association of childhood meat eating with presence of amnesic-MCI, from which we reported the incident rate ratio (IRR) [28]. Potential confounders considered, categorized as per Table 1, were age, sex, educational level, childhood SEP, current annual personal income, job type and current lifestyle factors (smoking status, alcohol use and current physical activity). Physical activity was measured by self-report using the Chinese version of the short International Physical Activity Questionnaire (IPAQ-C), categorized as per Table 1 [29]. Apart from age and sex these potential confounders were assessed according to a change-in-estimate criterion (at least $\geq 5 \%$ change) [30] for the estimates for the primary outcome to create parsimonious models. We present three models: Model 1 adjusted for age and sex; Model 2 additionally adjusted for education; Model 3 additionally adjusted for childhood and adulthood SEP and current exercise. Smoking status and alcohol use were not included in any model as they had a negligible effect on the estimates. In addition, we tested for trend across meat eating categories.

We also examined whether the associations of childhood meat eating with cognition were consistent by sex from the 


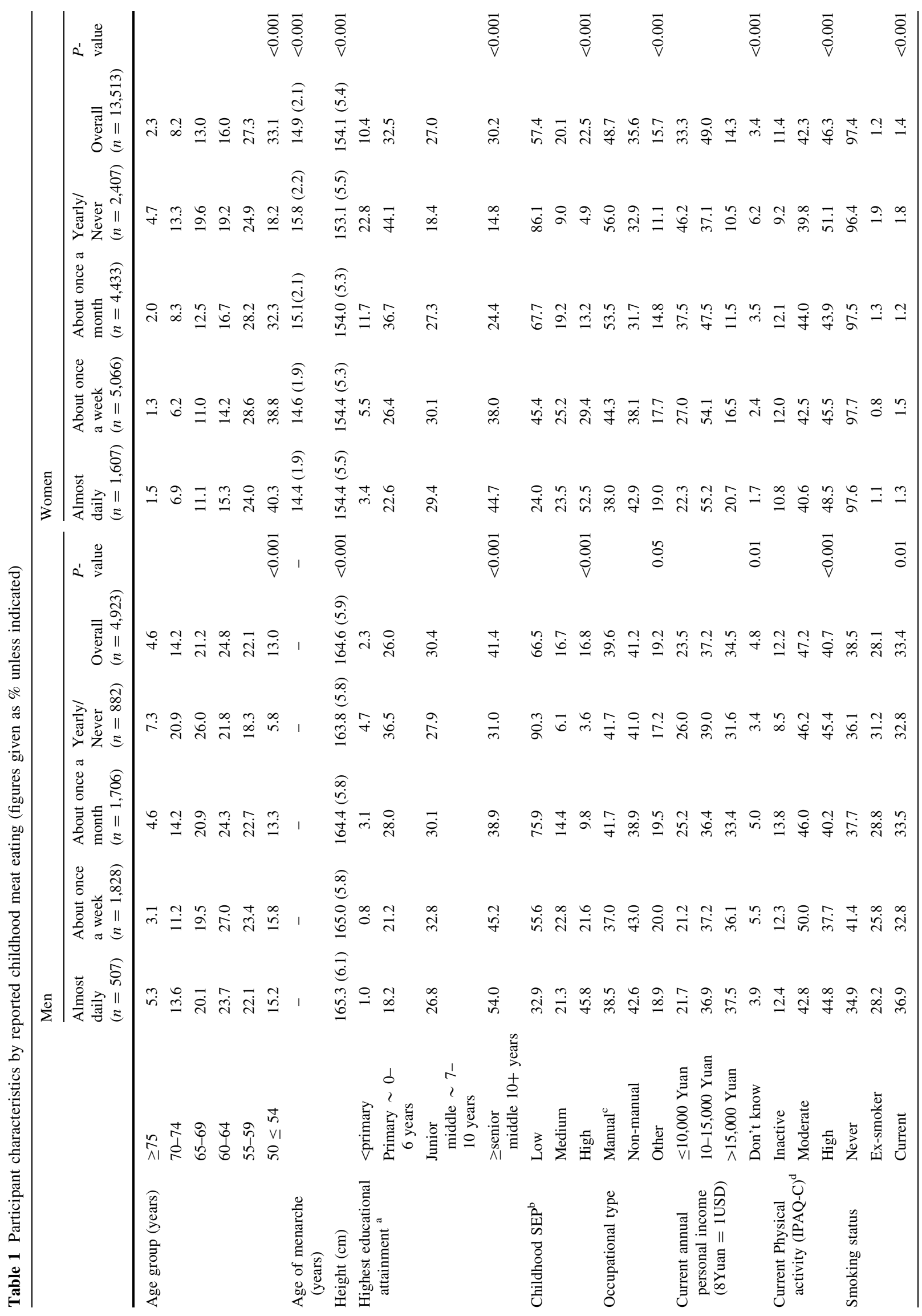




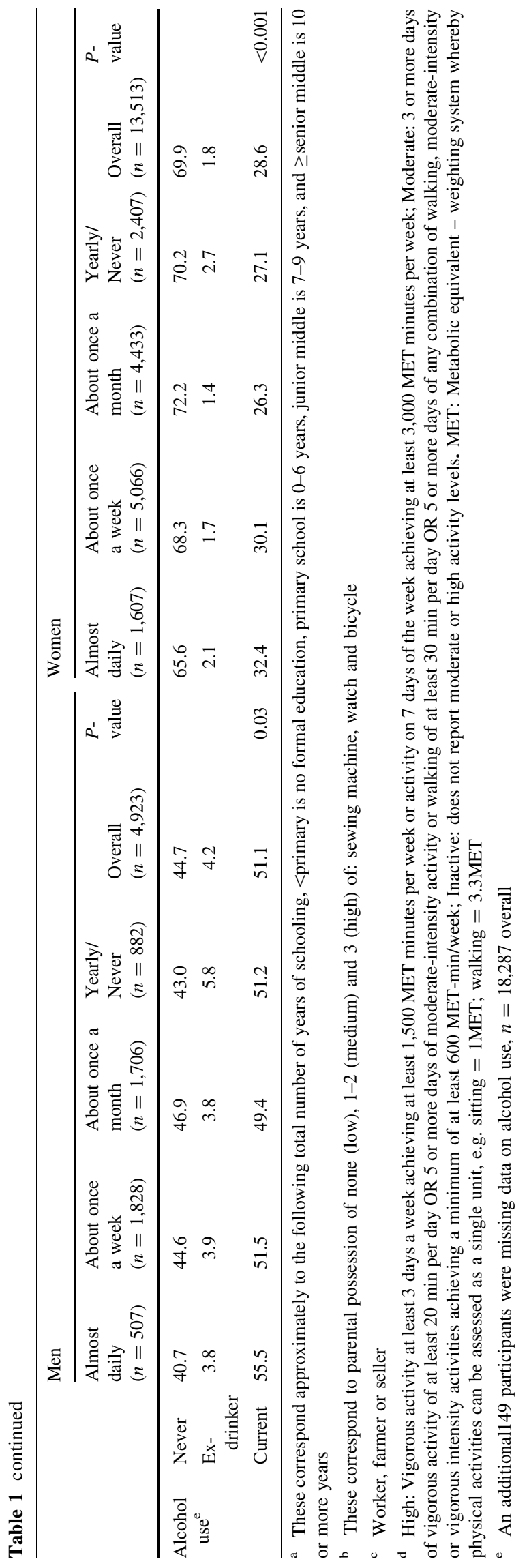

heterogeneity of associations across strata and significance of interaction terms between sex and childhood meat eating. In addition to allow for the association of meat eating with other confounding factors that may also have sexspecific associations with the outcomes we ran models that included an interaction term between sex and four other factors: age, childhood SEP, education and job type, and then assessed whether the additional interaction term between sex and childhood meat eating remained statistically significant. We similarly examined whether associations of meat eating were consistent by age by examining stratification by age-group (less than the median age of 59 years and greater than or equal to 59 years) and statistical significance of interaction term between age (continuous) and meat eating.

We used linear regression to assess the association of childhood meat eating with height (adjusted for age and sex) and with age of menarche as validation outcomes adjusting for sex.

Data analysis was done using STATA v8.2 (STATA Corporation, College Station, Texas).

\section{Results}

Of the 20,086 participants there were 5,381 men and 14,705 women. Of these, 4,923 men $(91 \%)$ and 13,513 women $(92 \%)$ had complete data for the outcome, validation outcomes (height and age of menarche), exposure and potential confounders (as used in Model 3, Table 3); these 18,436 participants were included in the final analysis. Data on age of menarche was missing for 86 women. Men were aged from 50 to 96 years, mean of $63.0 \pm 7.0$ years. Women were aged from 50 to 95 years, mean of $59.3 \pm 7.0$ years. Almost all of the participants $(98 \%)$ were Han Chinese. Childhood meat eating was similar in men and women, with $37.1 \%$ of men and $37.5 \%$ of women reporting meat eating about once a week. The men had more education with $71.7 \%$ of men and $57.2 \%$ of women having attended junior middle school or above. The prevalence of amnesic-MCI was slightly higher in men (13.3\%) than women $(11.5 \%)$.

Table 1 shows unadjusted associations between childhood meat eating and potential confounders. Childhood meat eating about once a week was associated with never smoking in men. Almost daily childhood meat eating was associated with higher educational attainment, higher childhood SEP, greater current personal income and current alcohol use. It was also associated with non-manual occupation in women.

Table 2 shows unadjusted associations between childhood meat eating and cognitive function by sex. Less frequent childhood meat eating (about once a month and 


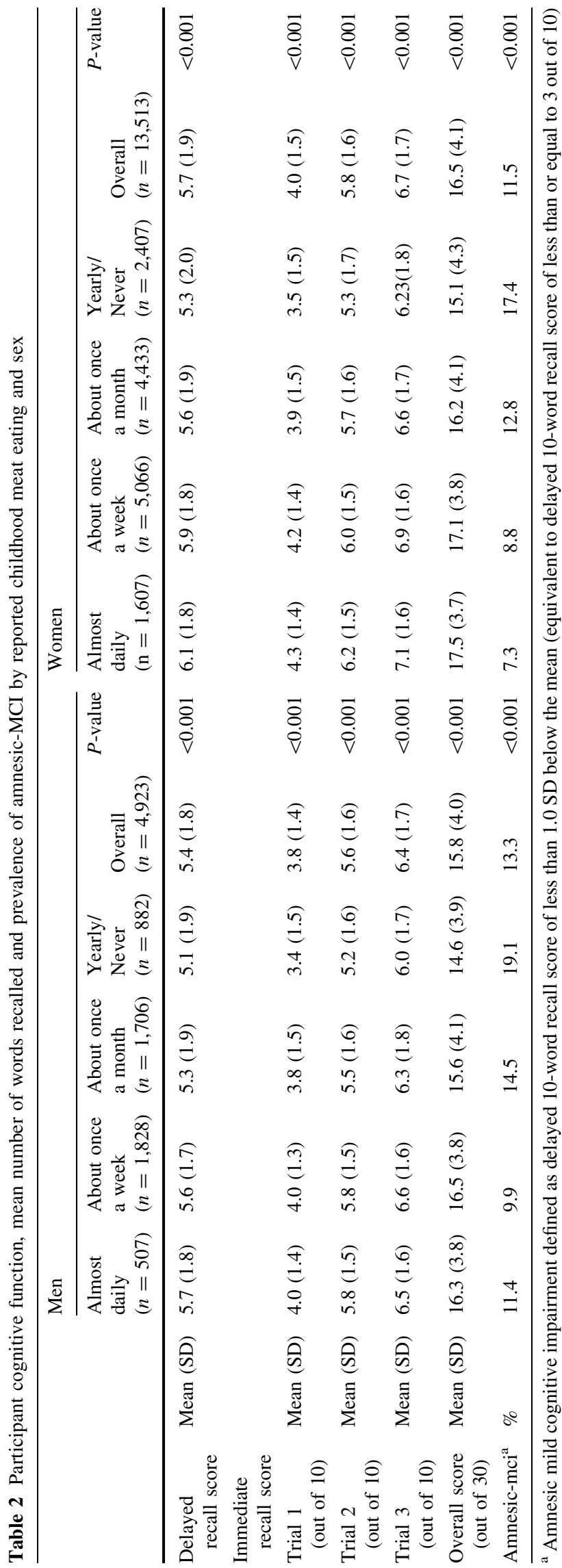

never or yearly) was associated with worse cognitive function in men and women.

There was no evidence from the heterogeneity of association across strata or statistical significance of interaction term between sex and childhood meat eating that the association of meat eating with delayed recall score or amnesic-MCI varied with sex or with age $(P$ values for interaction terms all $>0.19)$. There was some evidence from the statistical significance of the interaction term between sex and childhood meat eating that the association of meat eating with immediate recall score varied by sex and age ( $P$ value for interaction term 0.03 and 0.04 respectively). However, there was little heterogeneity of association by age group. Results are presented pooled by sex and age for all outcomes.

Table 3 shows adjusted associations between childhood meat eating and cognitive function. After adjustment for age, sex and education (Model 2), meat eating about once a week and almost daily, but not about once a month, were positively associated with delayed recall score and with lower risk of amnesic-MCI. Additional adjustment for childhood and adulthood SEP and current physical activity (Model 3) attenuated this association; although childhood meat eating almost daily remained positively associated with a higher delayed recall score. However, only childhood meat eating about once a week remained associated with risk of amnesicMCI, possibly due to smaller number of participants who recalled childhood meat eating almost daily $(n=2,114)$ compared to about once a week $(n=6,894)$. More frequent childhood meat eating (almost daily, about once a week and about once a month) when compared with never or yearly was associated with a higher immediate recall score in all models. After adjustment for age, education, childhood and adulthood SEP and current physical activity, more frequent meat eating, especially about once a week, was more strongly associated with immediate recall in men (adjusted difference in number of words recalled in men $=0.48[95 \%$ confidence interval $(\mathrm{CI})=0.17-0.78], 1.05[0.74,1.36]$, $0.78[0.36-1.21]$ and in women $=0.34[0.16-0.53], 0.60$ [0.41-0.79] and 0.73 [0.48-0.98] for childhood meat eating almost daily, about once a week and about once a month compared to yearly or never). The test for trend across meat eating categories was highly statistically significant in all models.

Table 4 shows adjusted associations of childhood meat eating with height (adjusted for age and sex) and unadjusted associations of childhood meat eating with age of menarche in women. Adjusted for age and sex, more frequent childhood meat eating (about once a month, about once a week and almost daily) was positively associated with height. Childhood meat eating about once a month, about once a week and almost daily were negatively associated with age of menarche. 
Table 3 Adjusted associations of childhood meat eating with cognitive function

\begin{tabular}{|c|c|c|c|c|c|c|}
\hline \multirow[b]{3}{*}{ Childhood meat eating } & \multicolumn{6}{|c|}{ Cognitive function as delayed 10 -word recall score } \\
\hline & \multicolumn{2}{|l|}{ Model 1} & \multicolumn{2}{|l|}{ Model 2} & \multicolumn{2}{|l|}{ Model 3} \\
\hline & $\begin{array}{l}\text { Adjusted difference } \\
\text { in no of words recalled }\end{array}$ & $95 \% \mathrm{CI}$ & $\begin{array}{l}\text { Adjusted difference } \\
\text { in no of words recalled }\end{array}$ & $95 \% \mathrm{CI}$ & $\begin{array}{l}\text { Adjusted difference } \\
\text { in no of words recalled }\end{array}$ & $95 \% \mathrm{CI}$ \\
\hline Never or yearly ${ }^{\mathrm{a}}$ & - & - & - & - & - & - \\
\hline About once a month & $0.12 * *$ & $0.04,0.20$ & 0.008 & $-0.07,0.08$ & 0.04 & $-0.04,0.11$ \\
\hline About once a week & $0.32 * * *$ & $0.24,0.40$ & $0.08 *$ & $0.006,0.16$ & 0.07 & $-0.003,0.15$ \\
\hline Almost daily & $0.57 * * *$ & $0.47,0.67$ & $0.26 * * *$ & $0.16,0.36$ & $0.22 * * *$ & $0.11,0.31$ \\
\hline$P$-value for trend & $<0.001$ & & $<0.001$ & & $<0.001$ & \\
\hline
\end{tabular}

Cognitive function as immediate 10 -word recall score

\begin{tabular}{|c|c|c|c|c|c|c|}
\hline \multirow[b]{2}{*}{ Childhood meat eating } & \multicolumn{2}{|l|}{ Model 1} & \multicolumn{2}{|l|}{ Model 2} & \multicolumn{2}{|l|}{ Model 3} \\
\hline & $\begin{array}{l}\text { Adjusted difference } \\
\text { in no of words recalled }\end{array}$ & $95 \% \mathrm{CI}$ & $\begin{array}{l}\text { Adjusted difference } \\
\text { in no of words recalled }\end{array}$ & $95 \% \mathrm{CI}$ & $\begin{array}{l}\text { Adjusted difference } \\
\text { in no of words recalled }\end{array}$ & $95 \% \mathrm{CI}$ \\
\hline Never or yearly ${ }^{a}$ & - & - & - & - & - & - \\
\hline About once a month & $0.72 * * *$ & $0.55,0.88$ & $0.42 * * *$ & $0.27,0.58$ & $0.38 * * *$ & $0.23,0.54$ \\
\hline About once a week & $1.47 * * *$ & $1.31,1.63$ & $0.85 * * *$ & $0.69,1.00$ & $0.73 * * *$ & $0.56,0.89$ \\
\hline Almost daily & $1.77 * * *$ & $1.56,1.98$ & $0.95 * * *$ & $0.75,1.16$ & $0.76^{* * * *}$ & $0.55,0.98$ \\
\hline$P$-value for trend & $<0.001$ & & $<0.001$ & & $<0.001$ & \\
\hline
\end{tabular}

Cognitive function as presence of amnesic-MCI ${ }^{\mathrm{c}}$

\begin{tabular}{|c|c|c|c|c|c|c|}
\hline & \multicolumn{2}{|l|}{ Model 1} & \multicolumn{2}{|l|}{ Model 2} & \multicolumn{2}{|c|}{ Model 3} \\
\hline & $\mathrm{IRR}^{\mathrm{b}}$ & $95 \% \mathrm{CI}$ & $\mathrm{IRR}^{\mathrm{b}}$ & $95 \% \mathrm{CI}$ & $\mathrm{IRR}^{\mathrm{b}}$ & $95 \% \mathrm{CI}$ \\
\hline Never or yearly ${ }^{a}$ & 1 & - & 1 & - & 1 & - \\
\hline About once a month & $0.88 *$ & $0.80,0.97$ & 0.97 & $0.88,1.06$ & 0.96 & $0.87,1.05$ \\
\hline About once a week & $0.65 * * *$ & 0.590 .72 & $0.81 * * *$ & $0.73,0.90$ & $0.84 * *$ & $0.75,0.93$ \\
\hline Almost daily & $0.57 * * *$ & $0.49,0.67$ & $0.78 * *$ & $0.67,0.92$ & 0.86 & $0.73,1.01$ \\
\hline$P$-value for trend & $<0.001$ & & $<0.001$ & & 0.002 & \\
\hline
\end{tabular}

Model 1: adjusted for age and sex

Model 2: additionally adjusted for education

Model 3: additionally adjusted for childhood and adulthood SEP, and current physical activity

a Reference category

b Incident rate ratio for amnesic mild cognitive impairment, with normal cognition as the reference category

c Amnesic mild cognitive impairment defined as delayed 10-word recall score of less than 1.0 SD below the mean (equivalent to delayed 10-word recall score of 3 or less out of 10)

*** $P<0.001$; ** $P<0.01$; * $P<0.05$

\section{Discussion}

In an understudied population of older Chinese, we found more frequent childhood meat eating was associated with better cognitive function in later life. These findings remained even after adjusting for childhood and adulthood SEP and current physical activity. Childhood meat eating almost daily was related to better delayed and immediate recall. There was also evidence of a dose response relation. Our findings are consistent with studies on animal protein intake and cognitive function in infants and children [8-10]. An adjusted difference of 0.22 words recalled [0.11-0.32] is likely to be clinically significant even at the individual level. Recent investigation of population representative data for delayed 10-word recall in China demonstrated a difference of 0.20 words recalled [95\% CI $0.2-0.3$ ], adjusted for age and sex, for each step increase in education level (primary, secondary and tertiary education) [31].

There are a number of potential limitations of the present study. First, we relied on recalled experience of 
Table 4 Adjusted associations of childhood meat eating with adulthood height in men and women (adjusted for age and sex) and unadjusted associations of childhood meat eating with age of menarche in women

\begin{tabular}{|c|c|c|c|c|c|c|c|}
\hline & \multicolumn{7}{|c|}{ Childhood meat eating } \\
\hline & \multirow[t]{2}{*}{ Yearly/Never $^{\mathrm{a}}$} & \multicolumn{2}{|c|}{ About once a month } & \multicolumn{2}{|c|}{ About once a week } & \multicolumn{2}{|c|}{ Almost daily } \\
\hline & & $\begin{array}{l}\text { Adjusted } \\
\text { difference }^{b}\end{array}$ & $95 \% \mathrm{CI}$ & $\begin{array}{l}\text { Adjusted } \\
\text { difference }^{\mathrm{b}}\end{array}$ & $95 \% \mathrm{CI}$ & $\begin{array}{l}\text { Adjusted } \\
\text { difference }^{b}\end{array}$ & $95 \% \mathrm{CI}$ \\
\hline Height $(\mathrm{cm})^{\mathrm{b}}$ & - & $0.24 *$ & $0.02,0.47$ & $0.54 * * *$ & $0.31,0.76$ & $0.76^{* * *}$ & $0.47,1.06$ \\
\hline Age of menarche (years) & - & $-0.71 * * *$ & $-0.81,-0.61$ & $-1.16 * * *$ & $-1.26,-1.06$ & $-1.39 * * *$ & $-1.52,-1.27$ \\
\hline
\end{tabular}

childhood meat eating which may have attenuated our findings to the null; however also means we cannot exclude the possibility that those with worse cognitive function may have been less likely to recall childhood meat eating. Random misclassification could have resulted in an over or underestimation of the findings [32], however our large sample compensates. Secondly, reported childhood meat eating may be a reflection of a cognitively protective current diet [33]. We did not adjust for potential confounding by diet, because of the difficulty of obtaining reliable and accurate dietary data in large-scale studies of free-living participants [34, 35], particularly amongst the Chinese who share several dishes during a meal and individual intake is doubly difficult to gauge. However, daily meat eating was associated with better childhood socioeconomic conditions, greater growth and earlier menarche. Thirdly, although we adjusted for several measures of childhood and adulthood SEP we cannot exclude residual confounding as childhood meat eating, as measured here, could be a proxy for other aspects of early living conditions, including maternal conditions and hence birth weight, childhood environment or a generally more nutritious diet. Fourthly, the measure of childhood nutrition, meat eating, is relatively crude, without timing, type or quantity. Meat intake could be a marker of total dietary protein intake. Childhood memories tend to date to no earlier than 3 or 4 years of age, or perhaps later in Chinese populations $[36,37]$ Childhood meat eating, as recorded here, probably reflects the memory of consumption after the age of 5 years, most likely of pork or chicken [38], in limited amounts [23, 39]. Consumption of animal foods and meat was and is comparatively low in this population [22, 23]. As such, our findings are perhaps more generalizable to developing countries with similar low levels of meat consumption. Fifthly, the infrastructure to facilitate fully representative studies in most developing countries, such as China, is not readily available. However, waiting until all the appropriate infrastructure is in place before embarking on studies from the developing world would preclude study of a large proportion of the global population during a period of immense transition. Although our sample could not be totally representative, this would invalidate our results only if we have systematically missed people with a specific relation between childhood meat eating and adulthood cognition-for example, if we are missing people with poor cognition who ate meat daily in childhood. Finally, we were unable to assess potential confounding effects of childhood cognitive abilities.

Despite these caveats, our findings add further evidence to support the importance of early life environment and long term cognitive function [5]. Meat contains important macro (i.e. protein and fat) and micro (e.g. iron, zinc, folic acid, vitamin B12 and arachidonic acid) nutrients required for neurological development of the hippocampus and the hypothalamus. These areas of the brain take the longest to mature during childhood and into adolescence; and are implicated in early Alzheimer disease [40].

\section{Conclusion}

A diet that includes a small amount of daily meat in childhood (after infancy) may have long-term positive effects on cognitive function. Alternatively childhood meat eating may reflect a generally more cognitively protective childhood environment and nutrition. Future research should examine the role of childhood exposures in long term cognitive development and if a role for childhood meat eating is verified, should elucidate the type and quantity of macro and micro nutrients that may be cognitively protective and the biological mechanisms behind these effects, so that preventive strategies can be implemented. Conversely, the long term effects of such nutrition for cardiovascular risk should also be evaluated. These results also highlight the childhood and adolescent antecedents of adult disease, with corresponding public health implications for healthy aging, if confirmed. 
Acknowledgments We thank R Peto and ZM Chen of the Clinical Trial Service Unit, The University of Oxford for their support. The Guangzhou Cohort Study investigators include: Guangzhou No. 12 Hospital: XQ Lao, WS Zhang, M Cao, T Zhu, B Liu, CQ Jiang (CoPI); The University of Hong Kong: CM Schooling, SM McGhee, GM Leung, R Fielding, TH Lam (Co-PI); The University of Birmingham: P Adab, GN Thomas, Y Peng, KK Cheng (Co-PI).

Funding This work was supported by the University of Hong Kong Foundation for Development and Research, Hong Kong; The University of Hong Kong University Research Committee Strategic Research Theme Public Health, Hong Kong; Guangzhou Public Health Bureau, and Guangzhou Science and Technology Committee, Guangzhou, China; and The University of Birmingham, Birmingham, UK.

Open Access This article is distributed under the terms of the Creative Commons Attribution Noncommercial License which permits any noncommercial use, distribution, and reproduction in any medium, provided the original author(s) and source are credited.

\section{References}

1. Ferri CP, Prince M, Brayne C, Brodaty H, Fratiglioni L, Ganguli $\mathrm{M}$, et al. Global prevalence of dementia: a delphi consensus study. Lancet. 2005;366(9503):2112-7.

2. Woo J, Kwok T, Sze FK, Yuan HJ. Ageing in China: health and social consequences and responses. Int J Epidemiol. 2002;31(4): $772-5$.

3. Snowdon DA, Kemper SJ, Mortimer JA, Greiner LH, Wekstein DR, Markesbery WR. Linguistic ability in early life and cognitive function and Alzheimer's disease in late life. Findings from the Nun Study. Jama. 1996;275(7):528-32.

4. Kaplan GA, Turrell G, Lynch JW, Everson SA, Helkala EL, Salonen JT. Childhood socioeconomic position and cognitive function in adulthood. Int J Epidemiol. 2001;30(2):256-63.

5. Heys M, Schooling CM, Jiang C, Adab P, Cheng KK, Lam TH, et al. Childhood growth and adulthood cognition in a rapidly developing population. Epidemiology. 2009;20(1):91-9.

6. Richards M, Wadsworth ME. Long term effects of early adversity on cognitive function. Arch Dis Child. 2004;89(10):922-7.

7. Kuklina EV, Ramakrishnan U, Stein AD, Barnhart HH, Martorell R. Growth and diet quality are associated with the attainment of walking in rural Guatemalan infants. J Nutr. 2004;134(12):3296300 .

8. Siegel EH, Stoltzfus RJ, Kariger PK, Katz J, Khatry SK, LeClerq $\mathrm{SC}$, et al. Growth indices, anemia, and diet independently predict motor milestone acquisition of infants in south central Nepal. J Nutr. 2005;135(12):2840-4.

9. Morgan J, Taylor A, Fewtrell M. Meat consumption is positively associated with psychomotor outcome in children up to 24 months of age. J Pediatr Gastroenterol Nutr. 2004;39(5): 493-8.

10. Neumann CG, Bwibo NO, Murphy SP, Sigman M, Whaley S, Allen LH, et al. Animal source foods improve dietary quality, micronutrient status, growth and cognitive function in Kenyan school children: background, study design and baseline findings. J Nutr. 2003;133(11 Suppl 2):3941S-9S.

11. Stein AD, Wang M, DiGirolamo A, Grajeda R, Ramakrishnan U, Ramirez-Zea M, et al. Nutritional supplementation in early childhood, schooling, and intellectual functioning in adulthood: a prospective study in Guatemala. Arch Pediatr Adolesc Med. 2008;162(7):612-8.

12. Welsh KA, Hoffman JM, Earl NL, Hanson MW. Neural correlates of dementia: regional brain metabolism (FDG-PET) and the
CERAD neuropsychological battery. Arch Clin Neuropsychol. 1994;9(5):395-409.

13. Prince M, Acosta D, Chiu H, Scazufca M, Varghese M. Dementia diagnosis in developing countries: a cross-cultural validation study. Lancet. 2003;361(9361):909-17.

14. Shankle WR, Romney AK, Hara J, Fortier D, Dick MB, Chen JM, et al. Methods to improve the detection of mild cognitive impairment. In Proceedings of the National Academy of Sciences of the United States of America. 2005 Mar 29;102(13):4919-24.

15. Ritchie K, Touchon J. Mild cognitive impairment: conceptual basis and current nosological status. Lancet. 2000;355(9199): 225-8.

16. Petersen RC. Mild cognitive impairment: current research and clinical implications. Semin Neurol. 2007;27(1):22-31.

17. Gauthier S, Reisberg B, Zaudig M, Petersen RC, Ritchie K, Broich K, et al. Mild cognitive impairment. Lancet. 2006; 367(9518):1262-70.

18. Mariani E, Monastero R, Mecocci P. Mild cognitive impairment: a systematic review. J Alzheimers Dis. 2007;12(1):23-35.

19. Jiang C, Thomas GN, Lam TH, Schooling CM, Zhang W, Lao X, et al. Cohort profile: The Guangzhou Biobank Cohort Study, a Guangzhou-Hong Kong-Birmingham collaboration. Int J Epidemiol. 2006;35(4):844-52.

20. Eckstein A. China's economic development: Ann Arbor: University of Michigan; 1975.

21. Maddison A. Chinese economic performance in the long run. Paris: OECD; 1998.

22. Ognjanovic S, Yamamoto J, Maskarinec G, Le Marchand L. NAT2, meat consumption and colorectal cancer incidence: an ecological study among 27 countries. Cancer Cause Control. 2006;17(9):1175-82.

23. Du S, Lu B, Zhai F, Popkin BM. A new stage of the nutrition transition in China. Public Health Nutr. 2002;5(1A):169-74.

24. Chan A, R. M, Unger J. Chen village under Mao and Deng. Berkeley, CA: University of California Press; 1992.

25. Parish WL, Whyte MK. Village and family life in contempory China. Chicago, IL: University of Chicago Press; 1978.

26. Whyte MK, Parish WL. Urban life in contemporary China. Chicago, IL: University of Chicago Press; 1984.

27. Schooling CM, Jiang CQ, Lam TH, Zhang WS, Cheng KK, Leung GM. Life-course origins of social inequalities in metabolic risk in the population of a developing country. Am J Epidemiol. 2008;167(4):419-28.

28. Barros AJ, Hirakata VN. Alternatives for logistic regression in cross-sectional studies: an empirical comparison of models that directly estimate the prevalence ratio. BMC Med Res Methodol. 2003;3:21.

29. Ihwiks. International Physical Activity Questionnaire. 2005.

30. Rothman KJ, Greenland S. Modern Epidemiology, vol. 2nd. Philadelphia: Lippincott-Raven; 1998.

31. Sosa AL, Albanese E, Prince M, Acosta D, Ferri CP, Guerra M, et al. Population normative data for the 10/66 Dementia Research Group cognitive test battery from Latin America, India and China: a cross-sectional survey. BMC Neurol. 2009;9:48.

32. Jurek AM, Greenland S, Maldonado G, Church TR. Proper interpretation of non-differential misclassification effects: expectations vs observations. Int J Epidemiol. 2005;34(3):680-7.

33. Pasinetti GM, Zhao Z, Qin W, Ho L, Shrishailam Y, Macgrogan $\mathrm{D}$, et al. Caloric intake and Alzheimer's disease. Experimental approaches and therapeutic implications. Interdiscip Top Gerontol. 2007;35:159-75.

34. Hebert JR, Clemow L, Pbert L, Ockene IS, Ockene JK. Social desirability bias in dietary self-report may compromise the validity of dietary intake measures. Int J Epidemiol. 1995;24(2):389-98.

35. Kipnis V, Midthune D, Freedman L, Bingham S, Day NE, Riboli $\mathrm{E}$, et al. Bias in dietary-report instruments and its implications 
for nutritional epidemiology. Public Health Nutrition. 2002;5(6): 915-23.

36. Davis N, Gross J, Hayne H. Defining the boundary of childhood amnesia. Memory (Hove, England). 2008;16(5):465-74.

37. Wang Q. Earliest recollections of self and others in European American and Taiwanese young adults. Psychol Sci. 2006;17(8): 708-14.

38. Leppman EJ. The Chinese Dietary Regime. Changing Rice Bowl: Economic development and diet in China. Hong Kong: Hong Kong University Press; 2005. p. 40-2.
39. Ognjanovic S, Yamamoto J, Maskarinec G, Le Marchand L. NAT2, meat consumption and colorectal cancer incidence: an ecological study among 27 countries. Cancer Causes Control. 2006;17(9):1175-82.

40. Kehoe P, Mallinson K, Bronzino J, McCormick CM. Effects of prenatal protein malnutrition and neonatal stress on CNS responsiveness. Brain Res. 2001;132(1):23-31. 